DOI: 10.14526/2070-4798-2019-14-3-26-29

\title{
Interconnections determination between coordinating abilities and the parameters of shooting from standing position among biathletes at the stage of sports specialization
}

\author{
Nikita A. Krukovskiy, Nikita N. Soshnikov* \\ Russian State University of Physical Culture, Sport, Youth and Tourism (SCOLIPC) \\ Moscow, Russia \\ ORCID: 0ooo-0oo3-3041-6026, krukovskiy-98@mail.ru \\ ORCID: oooo-002-5958-5694, Snn150@mail.ru*
}

\begin{abstract}
Crisis, connected with the training volumes and intensity limit, in the opinion of the scientists from different countries, can be solved by means of coordinating and technical training system development. The degree of marksmanship training manifestation and the tempo of shooting technique mastering are mainly conditioned by the level of coordinating abilities. Coordinating abilities are very important both for qualitative fulfillment of the separate technical elements and for the process of shooting training, organization and handling in general. Materials. We reveal the interconnections between the specific coordinating abilities of biathletes at the stage of sports specialization and their parameters of shooting from standing position. Research methods. Information sources analysis and summarizing, testing, graphical-mathematical method, experiment, methods of mathematical statistics. Results. For the first time we found the interconnections between the specific coordinating abilities of biathletes at the stage of sports specialization and the parameters of their shooting from standing position. Specific coordinating abilities were estimated with the help of the tests, created according to the criteria described in the book by Lyakh V.I. "Coordinating abilities: diagnostics and development". In shooting from standing position 3 parameters were estimated: time of the 1st shot, time of shooting, close grouping of shots. It is revealed that the leading coordinating abilities of biathletes, at the stage of sports specialization, are the abilities to feel the balance, to react quickly, to differentiate the parameters of movement. Other important abilities are the abilities to orient oneself in space and feel the rhythm. Conclusion. Interconnections determination will help to organize coordinating training taking into account weak points of marksmanship training.

Keywords: biathlon, coordinating abilities, specific coordinating abilities, shooting from standing position, interconnection between coordinating abilities and shooting from "standing" position.
\end{abstract}

For citation: Nikita A. Krukovskiy, Nikita N. Soshnikov* Interconnections determination between coordinating abilities and the parameters of shooting from "standing" position among biathletes at the stage of sports specialization. Russian Journal of Physical Education and Sport. 2019; 14(3): 26-29. DOI: 10.14526/2070-4798-2019-14-3-26-29

\section{INTRODUCTION}

R.A. Zubrilov writes “...sports results increase during recent years happened mainly owing to the results of cross country skiing improvement and the time of being at a shooting line decrease (firing rate increase), without the shooting quality loss and as a result we have results density increase" [3].

Crisis, connected with the training volumes and intensity limit, in the opinion of the scientists from different countries, can be solved by means of coordinating and technical training system development.

The degree of marksmanship training manifestation and the tempo of shooting technique mastering are mainly conditioned by the level of coordinating abilities. Coordinating abilities are very important both for qualitative fulfillment of the separate technical elements and for the process of shooting training, organization and handling in general.

The aim of the research is to reveal the interconnections between the specific coordinating abilities and the separate parameters of shooting from "standing" position.

The main objective of the research is to determine specific coordinating abilities, which correlate with the result of shooting from "standing" position among biathletes at the stage of sports specialization for further training process development optimization.

\section{MATERIALS AND METHODS}

10 people took part in the experiment - boys biathletes of the 1st and the 2nd sports categories. Practical part of the experiment was held on the basis of biathlon complex sports school for children 
and teen-agers (CSSCT) named after A. Elizarov.

The scientific research included three stages:

The first stage was held since February, 1, 2018 till April, 16, 2019 and included scientific-methodical literature analysis concerning the chosen topic. During this stage we defined specific coordinating abilities, which presumably influence the separate parameters of shooting from "standing" position:
2. The ability to feel the rhythm.

3. The ability to feel the balance.

4. The ability to differentiate movements parameters.

5. The ability to react.

6. The ability to realize voluntary muscular relaxation.

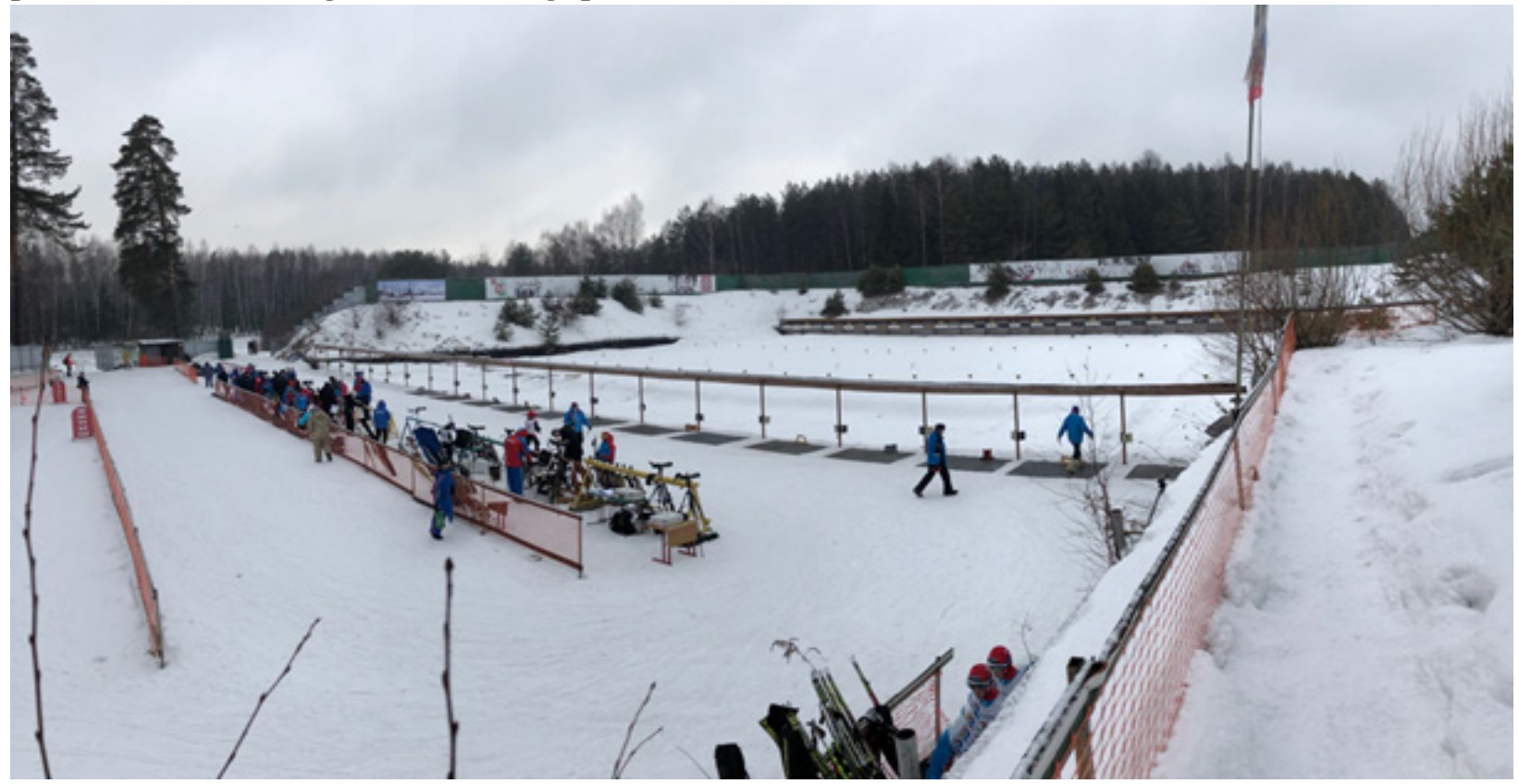

Picture 1 - Biathlon shooting range at sports school for children and teen-agers (CSSCT) named after A.

Elizarov

The result of the information sources analysis was the block of tests for coordinating abilities diagnostics (tests criteria are described in the book by Lyakh V.I. "Coordinating abilities: diagnostics and development" [4]):

1. Test in order to reveal the ability to orient oneself in space - a respondent puts a dot on a white sheet of paper, then he closes his eyes and makes a step backwards, makes a step forward and puts the second dot, trying to put it close to dot 1 . The result is measured by the distance between the dots.

2. Test in order to reveal the ability to feel the rhythm (subjective minute) - we need a stopwatch (electronic or mechanical). We note 30,45,60 seconds and etc., together with stopwatch the respondent counts time in his mind. When the respondent counts to 30 seconds, the time at a stopwatch is stopped. The difference between the time counted by the respondent in his mind and the time at a stopwatch is considered. The result is estimated in seconds.

3. Test in order to reveal the ability to keep the balance (Romberg's test) - is fulfilled standing on one leg, hands forward, fingers are slightly moved apart. The respondent stands with his eyes open for some time and then his steadiness is estimated without visual control over the balance (with his eyes close). The result is estimated in seconds.
4. Test in order to reveal the ability to differentiate the parameters of movements (Romberg position) the respondent drives up to the place, where the test will be held (Romberg's test), stops on the line and a stopwatch is switched on. The stopwatch is stopped when the respondent takes a steady Romberg position. The results are estimated in seconds.

5. Test in order to define the abilities to react (test-simulator for the speed of reaction https:// mozgion.ru/test-trenazher-na-skorost-reakcii/) - the respondent has 5 attempts, the best attempt forms the result. The aim is to touch the screen, when the light is green. The result is estimated in milliseconds.

6. Test in order to define the ability to a voluntary muscular relaxation (The accuracy of muscular efforts (AME)) - instead of carpal dynamometer (as it is demanded in a classical test), as an indicator we chose bench-type scales. The respondents had to press with the forefinger on the scale, with 3000 g. effort. The test is fulfilled with the eyes closed. The result is determined by the difference between the set effort and the effort, which was made by the respondent with his eyes closed.

The second stage included 6 chosen tests and a natural experiment on the basis of sports school for children and teen-agers (CSSCT) named after A. Elizarov. The second stage lasted since March, 3, 
2019 till March, 4, 2019.

After coordinating abilities test, the respondents shoot paper targets in terms of the training process. By order of a coach athletes shot with the intensity, which corresponded with the 1st (130-150 beats/ minute) and the 2nd (151-170 beats/minute) zones of intensity. [5]

We chose the following indices as the evaluation criteria for shooting from standing position:

The time of the 1st shot - from the moment of being on a mat and till the fits shot fulfillment (sec.)

The time of shooting - from the moment of being on a mat and till the biathlete leaves the mat (sec.)

Fire dispersion - was estimated as the average distance of the holes from the dispersion center (DC). In order to define DC we chose graphicmathematical method, which is the most suitable method for a biathlete, as writes R.A. Zubrilov.

At the third stage since March, 9, 2019 till April, 25, 2019, we handled and analyzed the results of the research. Taking into account the results of the research we made some recommendations concerning the trainings for the leading and important specific coordinating abilities development among biathletes at the stage of sports specialization.

\section{RESULTS AND DISCUSSION}

Analyzing the received results, we counted correlation between coordinating abilities indices and the results of shooting from standing position.

In "the time of the first shot" index there was strong interconnection with "the ability to orient oneself in space" index in the 1st zone of intensity $r$ $=0,98$ with "the ability to react" index $\mathrm{r}=0,88$.

In "time of shooting" index there was a strong interconnection with "ability to feel the rhythm" index at the 2nd zone of intensity $r=0,73$ and the index of parameters of movements differentiation at the 2nd zone of intensity $r=0,78$.

In "fire dispersion" index there was a strong interconnection at the 2 nd zones of intensity with the test results for the ability estimation to differentiate the parameters of movements $r=0,9$, the test results to estimate the abilities to feel the rhythm $\mathrm{r}=$ 0,64 and the test results for estimation of the ability to feel the balance $r=0,68$.We also revealed strong interconnection with "fire dispersion" parameters at the 1st zone of intensity between the test for the ability to feel the balance $\mathrm{r}=0,7$.

Information indices of specific coordinating abilities, which influence the indices of shooting from "standing" position, among biathletes at the stage of sports specialization are the following:

1. Influencing "the time of the 1st shot"

- Results of test in order to determine the ability to orient oneself in space at the 1st zone of intensity

$\mathrm{r}=0,98$ and maximum results at the 1st and the 2nd zones of intensity максимальные $\mathrm{r}=0,73$
- Results of test in order to estimate the ability to react (test-simulator for the speed of reaction https://mozgion.ru/test-trenazher-na-skorostreakcii/) at the 1st zone of intensity $r=0,88$

- Results of test in order to estimate the ability to differentiate the parameters of movements (Romberg position) maximum indices of the test at the 1st and the 2nd zones of intensity $r=0,89$

2. Influencing "the time of shooting"

- Results of test in order to estimate the ability to feel the rhythm (subjective minute) at the 2nd zone of intensity $r=0,73$

- Results of test in order to estimate the ability to differentiate the parameters of movements (Romberg position) at the 2nd zones of intensity $\mathrm{r}$ $=0,78$ and maximum results at the 1st and the 2nd zones of intensity $r=0,89$

3. Influencing "fire dispersion"

- Results of test in order to estimate the ability to differentiate the parameters of movements (Romberg position) $r=0,9$ and maximum results at the 1st and the 2nd zones of intensity $r=0,8$.

- Results of test in order to estimate the ability to react (test-simulator for the speed of reaction https://mozgion.ru/test-trenazher-na-skorostreakcii/) at the 2nd zone of intensity $r=0,64$

- Results of test in order to estimate the ability to feel the balance (Romberg's test) at the 1st and the 2nd zones of intensity $r=0,7$ and maximum results at the 1st and the 2nd zones of intensity $r=0,7$.

Thus, the leading coordinating abilities of biathletes, at the stage of sports specialization, are the abilities to feel the balance, to react quickly, to differentiate the parameters of movement. Other important abilities are the abilities to orient oneself in space and feel the rhythm.

\section{References}

1. Volodin A.A. Technology of coordinating abilities upbringing among young rifle shooters at the stage of sports specialization. Candidate's thesis. Moscow. 2015: 25.

2. Baydychenko T.V., Arkhipova E.A. Coordinating abilities development among rifle shooters of high qualification. Teoriya i metodika fizicheskoi kultury i sporta. Kiev. 2011; 4: 114 (In Russ.).

3. Zubrilov R.A. Strlkovaya podgotovka biatlonistov [Marksmanship training of a biathlete: monograph]. Moscow: Soviet sport. 2013: 296.

4. Lyakh V.I. Koordinacionnye sposobnosti: diagnostika I razvitie [Coordinating abilities: diagnostics and development]. Moscow: TVT Divizion. 2006: 290.

5. Ramenskaya T.I., Batalov A.G. Lyzhnye gonki: uchebnik [Cross-country skiing: textbook]. Moscow: "Buki Vedi". 2015: 564.

6. Burgomaster K.A., Howarth K.R., Phyllips S.M., Rakobowchuk M., Mcdonald M.J., McGee 
S.L., Gibala M.J. Similar metabolic adaptations during exercise after low volume sprint interval and traditional endurance training in humans. Journal of Applied Physiology. 2008; 586(1): 151-160.

7. Gibala M.J., Little J.P., Mcdonald M.J., Hawley J.A. Physiological adatpations to low-volume, highintensity interval training in health and disease. The Journal of Physiology. 2012; 590(Pt5): 1077-1084. DOI: 10.1113/jphysiol.2011.224725.

8. Hopkins W.G., Marshall S.W., Batterham A.M., Hanin J. Progressive statistics for studies in sports medicine and exercise science. Medicine and Science in Sports and Exercise. 2009; 41(1): 3-13. DOI: 10.1249/MSS.obo13e31818cb278.

9. Laursen P.B. Training for intense exercise performance: high-intensity or high-volume training? Scandinavian Journal of Medicine and Science in Sports. 2010; 20(Suppl.2): 1-10. DOI: 10.1111/j.1600-0838.2010.01184.x

10. Saunders P.U., Pyne D.B., Telford R.D., Hawley J.A. Reliability and variability of running economy in elite distance runners. Medicine and Science in Sports and Exercise. 2004; 36: 19721976. DOI: 10.1249/01.MSS.0000145468.17329.9F.

11. Tomlin D.L., Wenger H.A. The relationship between aerobic fitness and recovery from high intensity intermittent exercise. Sports Medicine. 2001; 31(1): 1-11. DOI: 10.2165/00007256200131010-00001.

\section{Submitted: 06.07.2019}

Author's information:

Nikita A. Krukovskiy - Bachelor of Physical Culture, Russian State University of Physical Culture, Sport, Youth and Tourism, 150122, Russia, Moscow, Sirenivyi blv., House 4, e-mail: krukovskiy-98@mail. $\mathrm{ru}$

Nikita N. Soshnikov - Lecturer, Russian State University of Physical Culture, Sport, Youth and Tourism, 150122, Russia, Moscow, Sirenivyi blv., House 4, e-mail: Snn150@mail.ru 